\title{
PENILAIAN STATUS DOMAIN SUMBER DAYA IKAN LEMURU DENGAN PENDEKATAN EKOSISTEM YANG DIDARATKAN DI PPI KEDONGANAN, BALI
}

\author{
Ni Ketut Tika Suariningsih", I Wayan Restu, Made Ayu Pratiwi \\ Program Studi Manajemen Sumberdaya Perairan, Fakultas Kelautan dan Perikanan, Universitas Udayana \\ *Email: tika.1ningsih@gmail.com
}

\begin{abstract}
STATUS ASESSMENT OF LEMURU FISH RESOURCES DOMAIN BASED ON THE ECOSYSTEM APPROACH AT PPI KEDONGANAN, BALI
\end{abstract}

PPI Kedonganan is a fish landing base located in Kedonganan Village, Kuta District, Badung Regency. One of the fish commodities that landed at PPI Kedonganan is Lemuru Fish (Sardinella lemuru). The high rate of catching Lemuru must be balanced with proper management so that Lemuru Fish Resources remain sustainable. This study was conducted to determine the status of the utilization of Lemuru fish resources. The study was conducted from January 2021 to March 2021. Data collection was carried out by observation and interviews. Data analysis of each indicator was carried out using a multi-criteria analysis approach with composite index assessment and visualization by flag model. Indicators were observed the trends of fish size, the proportion of juvenile fish were caught, the species composition, range collapse of fish resources, Endangered, Threatened, and Protected species. The status assessment of the Lemuru resource domain which landed at PPI Kedonganan is in the good category with a composite value of 66.7. Results of the trend indicators of fish size is relatively fixed, the proportion of fish juvenile caught about $90 \%$, the composition of species caught was $100 \%$ of the target fish i.e, lemuru that caught by using gill net, range collapse of fish resources as much as $57 \%$ of fishermen expressed relatively fixed in looking for fishing grounds, and ETP species not found.

Keywords: EAFM; Lemuru Fish; Fisheries Management; PPI Kedonganan.

\section{PENDAHULUAN}

Ikan pelagis hidup berada pada kolom perairan, memiliki ciri hidup bergerombol. Ciri lain dari ikan pelagis yaitu dapat berenang bebas sehingga dapat bermigrasi mendekati permukaan perairan. Ikan pelagis kecil memiliki peranan penting sebagai elemen dalam ekosistem yaitu memiliki peranan penting dalam tingkatan trofik atas dan bawah distruktur trofik (Freon et al., 2005). Sumber daya ikan pelagis kecil contohnya, ikan teri (Stolephorus indicus), japuh (Dussumieria spp), siro (Amblygaster sirm), layang (Decapterus sp.), kembung (Rastrellinger spp) dan lemuru (Sardinella sp.) yang mempunyai nilai ekonomis tinggi, sehingga banyak ditangkap (PPNP, 2014).

Kelurahan Kedonganan merupakan salah satu wilayah yang memiliki Pangkalan Pendaratan Ikan (PPI) yang berada pada (Pratiwi et al., 2020). Potensi perikanan yang didaratkan di PPI Kedonganan memiliki peluang yang besar bagi pengguna pemanfaatannya. Pemanfaatan sumber daya ikan dapat memberikankan manfaat kepada pelaku usaha secara ekonomi dan memberikan dampak eksternalitas yang positif ataupun negatif (Desniarti et al., 2006). Data produksi dari UPT Pangkalan Pendaratan Ikan (PPI) Kedonganan, ikan pelagis kecil dominan 
selama lima tahun terakhir didominasi oleh Ikan Lemuru dengan jumlah produksi 3.336,895 ton (PPI Kedonganan, 2019). Hasil produksi ikan akan memengaruhi kelimpahan sumber daya ikan. Dengan ini pengelolaan perikanan perlu dilakukan dengan tepat agar sumber daya ikan dapat bermanfaat bagi makhluk hidup secara berkelanjutan.

Pengoptimalan terhadap sumber daya ikan dapat dilakukan dengan pendekatan melakukan pengelolaan pada perikanan yang berbasis ekosistem atau EAFM (Ecosystem Approach to Fisheries Management). EAFM secara sederhana sebagai konsep dalam meyeimbangkan antara sosial ekonomi dengan pengelolaan perikanan yang dilakukan dengan mempertimbangkan seluruh aspek mulai dari biotik dan abiotik. Dalam pelaksanaan penerapan EAFM terdapat 6 domain salah satunya yaitu domain sumber daya ikan, dimana masing-masing domain terdapat indikator (NWG EAFM, 2014).
Indikator pada domain sumber daya ikan yang digunakan sebagai acuan dalam penelitian yaitu, Catch per unit effort (CPUE) baku, tren ukuran ikan, proporsi ikan yuwana yang ditangkap, komposisi spesies, range collapse, dan ETP (Endangered Threatened Protected species). Perangkat indikator tersebut sebagai alat monitoring dan evaluasi untuk mengetahui penilaian status ikan pelagis kecil yang didaratkan di PPI Kedonganan. Berdasarkan pemaparan diatas, penelitian ini penting dilakukan agar dapat memberikan saran pengelolaan terhadap perikanan pelagis kecil yang didaratkan di PPI Kedonganan dengan pendekatan ekosistem.

\section{METODOLOGI}

\subsection{Waktu Penelitian dan Lokasi Penelitian}

Penelitian berlokasi di PPI Kedonganan, Bali dari Bulan Januari hingga Maret 2021 dengan 6 kali pengambilan sampel.

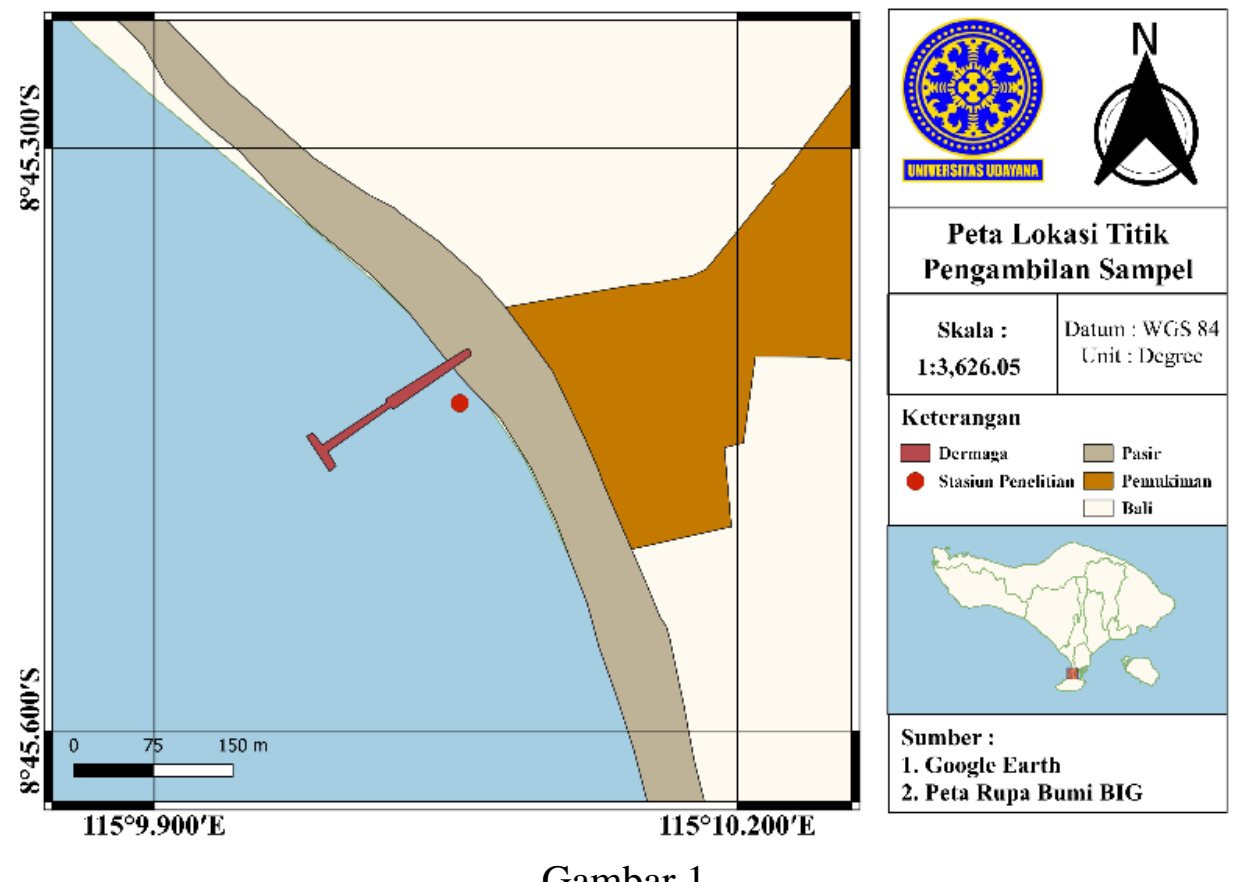

Peta Lokasi Penelitian di PPI Kedonganan

\subsection{Teknik dan Pengumpulan Data}

\subsubsection{Pengukuran Indikator}

Indikator yang diamati yaitu komposisi ikan yuwana yang ditangkap, tren ukuran ikan, range collapse sumber daya ikan, komposisi spesies hasil tangkapan, dan spesies ETP (Endangered, Threatned, and Protection). Kriteria dan bobot penilaian pada setiap indikator memiliki penilaian yang berbeda (Modifikasi dari NWG EAFM, 2014). 
Tabel 1. Kriteria dan Bobot Domain Sumber Daya Ikan dalam EAFM

\begin{tabular}{|c|c|c|c|c|}
\hline No. & Indikator & Jenis Data & Kriteria & $\begin{array}{c}\text { Bobot } \\
(\%)\end{array}$ \\
\hline 1. & Ukuran Ikan & $\begin{array}{l}\text { Observasi } \\
\text { Wawancara }\end{array}$ & $\begin{array}{l}1=\text { ikan yang ditangkap semakin kecil } \\
2=\text { ikan yang ditangkap relatif tetap } \\
3=\text { ikan yang ditangkap semakin besar }\end{array}$ & 33,3 \\
\hline 2. & $\begin{array}{l}\text { Proporsi } \\
\text { Ikan } \\
\text { Yuwana } \\
\text { yang } \\
\text { tertangkap }\end{array}$ & Observasi & $\begin{array}{l}1=\text { banyak sekali ikan yuwana }(>60 \%) \\
2=\text { banyak ikan yuwana }(30-60 \%) \\
3=\text { sedikit ikan yuwana }(<30 \%)\end{array}$ & 25 \\
\hline 3. & $\begin{array}{l}\text { Komposisi } \\
\text { Spesies }\end{array}$ & $\begin{array}{l}\text { Observasi } \\
\text { Wawancara }\end{array}$ & $\begin{array}{l}1 \text { = ikan utama lebih sedikit }(<15 \% \text { dari total } \\
\text { volume) } \\
2=\text { ikan utama sama dengan ikan sampingan(16- } \\
30 \% \text { dari total volume) } \\
3=\text { ikan utama lebih banyak ( }>31 \% \text { dari total } \\
\text { volume) }\end{array}$ & 16,7 \\
\hline 4. & $\begin{array}{l}\text { Range } \\
\text { Collapse }\end{array}$ & Wawancara & $\begin{array}{l}1=\text { daerah penangkapan menjadi sangat jauh } \\
2=\text { daerah penangkapan jauh } \\
3=\text { daerah penangkapan relative tetap jaraknya }\end{array}$ & 16,7 \\
\hline 5. & $\begin{array}{l}\text { Spesies ETP } \\
\text { (Endangered } \\
\text { species, } \\
\text { Threatned } \\
\text { species, and } \\
\text { Protection } \\
\text { species) }\end{array}$ & $\begin{array}{l}\text { Observasi } \\
\text { Wawancara }\end{array}$ & $\begin{array}{l}1=>1 \text { tangkapan spesies ETP } \\
2=\text { jumlah tangkapan spesies ETP } 1 \\
3=\text { jumlah tangkapan spesies ETP } 0 \text { atau tidak ada }\end{array}$ & 8,3 \\
\hline
\end{tabular}

\subsubsection{Analisis Data}

1. Tren Ukuran Ikan

Sebaran frekuensi ukuran panjang ikan dapat menggunakan rumus sebagai berikut (Sudjana, 2002).

$K=1+3,3 \log (n)$

$C=W / K$

Keterangan :

$\mathrm{K}=$ Jumlah kelas.

$\mathrm{n}=$ Jumlah data.

$\mathrm{C}=$ Selang kelas.

$\mathrm{W}=$ Panjang selang (Pmaksimum Pminimum).

2. Proporsi Ikan Yuwana yang Ditangkap Proporsi ikan yuwana dapat dicari dengan jumlah ikan yuwana yang tertangkap dibagi jumlah total hasil tangkapan ikan dari seluruh alat tangkap. Menurut NWG EAFM (2014) rumus untuk menghitung proporsi ikan yuwana adalah sebagai berikut:
$P C y=\frac{C y i}{C t o t} \times 100 \%$

Keterangan :

Pcy $=$ proporsi yuwana yang ditangkap (\%).

Cyi = ikan yuwana yang ditangkap (ton).

Ctot $=$ total hasil ikan (ton).

(Sumber: NWG EAFM, 2014).

3. Komposisi Spesies

Komposisi spesies dapat dicari dengan rumus :

$K s=\frac{n i}{N} \times 100 \%$

Range Collapse Sumber Daya Ikan

Penentuan range collapse sumber daya ikan diapat berdasarkan hasil wawancara dengan nelayan terkait kondisi daerah penangkapan ikan untuk mengetahui apakah terjadi perubahan daerah penangkapan ikan (fishing ground) yang mengakibatkan semakin sulit nelayan untuk menangkap ikan atau sebaliknya. 
4. Spesies ETP

Untuk mengetahui kondisi ataupun keadaaan dari Spesies ETP (Endangered, Threatned, and Protection) ini dapat dilakukan dengan observasi pengamatan di lapangan saat penelitian dilakukan serta hasil dari wawancarai dengan nelayan.

\subsubsection{Analisis Penilaian EAFM}

Berdasarkan Modul NWG EAFM (2014) untuk analisis penilaian dalam menentukan hasil EAFM terdiri dari tiga tahap sebagai berikut:

1. Menilai Setiap Indikator

Penilaian menggunakan skor yang memiliki nilai 1,2,3 kemudian disesuaikan dengan kriteria penilaian masing-masing indikator. Penelitian ini berfokus pada 5 idikator. Kriteria penilaian dapat dilihat pada Tabel 1.

2. Nilai Indeks

Nilai indeks diperoleh dengan mengalikan nilai skor dengan bobot dari setiap indikator. Menurut NWG EAFM (2014) rumus yang digunakan adalah:

Cat $-i=S a t-i \times W-i$

Keterangan :

Cat ke $\mathrm{i}=$ Nilai ke- $\mathrm{i}$

Sat ke i $\quad=$ Skor ke-i

$\mathrm{W}$ ke $\mathrm{i} \quad=$ Bobot ke-I (bobot sudah ditetapkan)

(Andrianto, $d k k ., 2014$ )

3. Nilai Komposit

Menurut NWG EAFM (2014) menghitung nilai komposit menggunakan rumus sebagai berikut:

$$
\text { Nilai Komposit }-i=\frac{\text { Cat }-i}{\text { Cat }-i \max } \times 100(6)
$$

Keterangan :

Cat ke i = Nilai indeks total semua indikator

Cat maximum = Nilai indeks total maksimum

(Andrianto, $d k k ., 2014$ )

Tabel 2. Penggolongan Nilai Indeks Komposit dan Visualisasi Model Bendera

\begin{tabular}{ccc}
\hline Rentang Nilai Komposit & Model Bendera & Deskripsi \\
\hline $1-20$ & & Buruk \\
$21-40$ & Kurang \\
$41-60$ & Sedang \\
$61-80$ & Baik \\
$81-100$ & Baik Sekali \\
\hline
\end{tabular}

\section{HASIL DAN PEMBAHASAN}

\subsection{Kondisi Sumber Daya Ikan Lemuru di PPI Kedonganan}

Pantai Kedonganan merupakan salah satu pantai yang memiliki pelabuhan perikanan tipe $\mathrm{D}$ yang memafaatkan sumberd aya ikan di wilayah pengelolaan (WPP) RI 573 yaitu Pangkalan Pendaratan Ikan (PPI) Kedonganan. Nelayan yang mendaratkan ikan di PPI Kedonganan sebagian besar berasal dari Banyuwangi namun sudah menetap dan tinggal di Desa Kedonganan. PPI Kedonganan sebagai pendaratan ikan memiliki karakteristik pantai yaitu struktur pasir berwarna putih dan memiliki ombak yang sedang.

Kondisi sumber daya perikanan lemuru yang didaratkan di PPI Kedonganan pada 5 tahun terakhir mengalami penurunan di tahun 2017. Berdasarkan informasi dari nelayan penurunan tersebut diduga karena curah hujan yang tinggi selama beberapa waktu yang panjang sehingga nelayan tidak dapat melakukan penangkapan ikan dan mengakibatkan musim paceklik bagi para nelayan. Hasil produksi sumberdaya ikan yang didaratkan di PPI kedonganan selama 5 tahun terdiri dari berbagai macam spesies ikan yang terdiri dari ikan pelagis besar dan kecil. 
Berdasarkan data produksi PPI Kedonganan tahun 2020, ikan lemuru sebagai ikan dominan dari hasil produksi sumberdaya ikan selama 5 tahun terakhir.

Tabel 3. Data Hasil Produksi Sumberdaya Ikan di PPI Kedonganan

\begin{tabular}{ccc}
\hline Tahun & $\begin{array}{c}\text { Jumlah Produksi Seluruh } \\
\text { Ikan (Ton) }\end{array}$ & $\begin{array}{c}\text { Jumlah Produksi Ikan } \\
\text { Lemuru (Ton) }\end{array}$ \\
\hline 2016 & $4.087,520$ & $1.302,958$ \\
2017 & $2.195,800$ & 106,180 \\
2018 & $4.740,690$ & 127,396 \\
2019 & $6.429,720$ & 870,780 \\
2020 & $5.304,390$ & 929,581 \\
\hline
\end{tabular}

\subsection{Tren Ukuran Ikan}

Hasil tren ukuran ikan pada saat pengambilan data terdapat perbedaan dengan tren ukuran kan pada penelitian tahun 2018. Penelitian yang dilakukan oleh Pertami (2018) didapat ikan lemuru dengan rata-rata ukuran $13,7 \mathrm{~cm}$ sedangkan pada penelitian ini didapat ikan lemuru dengan rata-rata $13,0 \mathrm{~cm}$. Hasil penelitian ini mengalami penurunan sebesar 0,7 cm dari ukuran ikan lemuru tahun 2018 . Hal tersebut menggambarkan bahwa ikan lemuru masih dalam kategori tidak jauh berbeda atau relatif tetap dari tahun-tahun sebelumnya.

Tabel 4. Perbandingan Ukuran Ikan Lemuru

\begin{tabular}{lll}
\hline \multicolumn{1}{c}{ Sumber } & \multicolumn{1}{c}{ Lokasi } & Ukuran Rata-rata (cm) \\
\hline $\begin{array}{l}\text { Nyoman Dati Pertami } \\
(2018)\end{array}$ & Selat Bali (Perairan Jimbaran) & 13,7 \\
Penelitian ini (2021) & $\begin{array}{l}\text { Perairan Jimbaran, Kedonganan, Kuta, } \\
\text { Ungasan }\end{array}$ & 13,0 \\
\hline
\end{tabular}

Berdasarkan hasil wawancara yang telah dilakukan, terdapat $80 \%$ responden yang menyatakan ukuran ikan dari tahun ke tahun relatif tetap dikarenakan daerah penangkapan ikan masih sama seperti daerah penangkapan pada tahun-tahun sebelumnya yaitu berada di perairan Kedonganan, Kuta, dan Ungasan. Kemudian, terdapat $10 \%$ yang menyatakan ukuran ikan semakin kecil dan $10 \%$ yang menyatakan bahwa ukuran ikan semakin bertambah besar. Panjang total minimum yang didapat yaitu $11,5 \mathrm{~cm}$ dan panjang maksimum $14,5 \mathrm{~cm}$. Ikan lemuru yang tertangkap masuk ke dalam golongan ikan portolan yang memiliki ukuran panjang 11-15 cm (Merta, 1992).

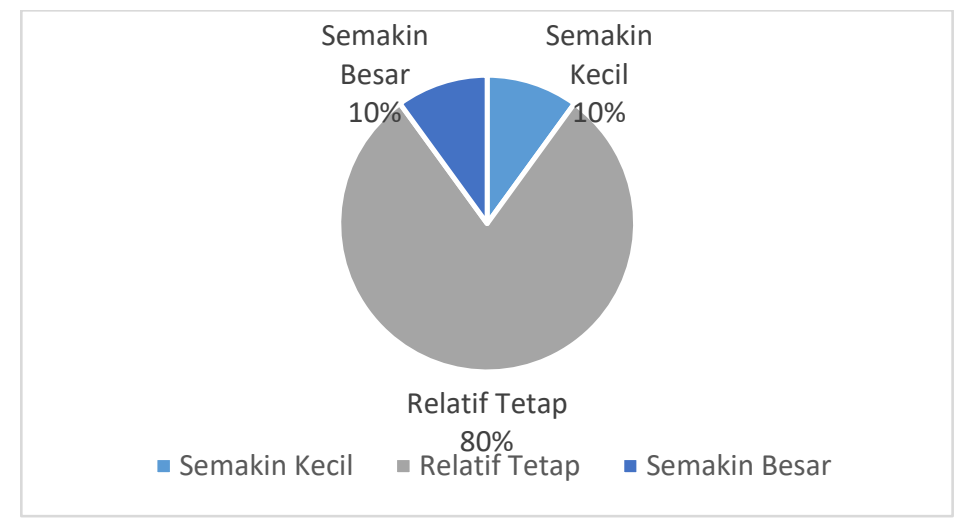

Gambar 2.

Persentase Tren Ukuran Ikan 
Ikan lemuru pada penelitian ini termasuk kedalam golongan protolan. Hal ini disebabkan karena memiliki rentang ukuran 115 -145 mm dan alat tangkap yang digunakan berupa gill net dengan ukuran 1 inci. Berdasarkan hasil wawancara tren ukuran ikan lemuru memiliki ukuran yang relatif tetap. Penelitian dilakukan oleh Putra et al., (2020) di perairan Selat Bali, nilai FL ikan lemuru yang didapat berukuran panjang 120-149 mm dengan sebaran frekuensi paling tinggi pada selang kelas panjang 135-137. Hasil penelitian Pertami et al., (2018) menyatakan nilai rerata ukuran ikan lemuru pada penelitian di perairan Selat Bali memiliki ukuran 137 mm. Kondisi ini mendakan bahwa ukuran panjang ikan yang didaratkan di PPI Kedonganan relatif tetap atau tidak jauh berbeda dari ukuran penelitian sebelumnya yang dilakukan pada perairan Selat Bali.

\subsection{Proporsi Ikan Yuwana yang Tertangkap}

Ikan yuwana merupakan ikan yang belum matang gonad atau belum dapat melakukan proses pemijahan. Ikan lemuru betina matang gonad memiliki panjang berkisar 17,64-18,30 cm dan ikan lemuru jantan memiliki panjang berkisar 17,99-18,50 $\mathrm{cm}$ (Pertami et al., 2018). Hasil yang didapat yaitu $100 \%$ dari total tangkapan nelayan, ikan yang tertangkap termasuk ikan yuwana (juvenile). Hasil tangkapan tersebut menandakan bahwa status sumber daya ikan pada indikator Proporsi Ikan Yuwana (Juvenile) termasuk dalam kondisi buruk dengan nilai skor 1. Dominansi ikan yuwana dipengaruhi oleh penggunaan alat tangkap dengan jaring insang ukuran 1 inci yang merupakan jaring dengan ukuran penangkapan ikan lemuru protolan. Ukuran pada mata jaring dapat memengaruhi hasil tangkapan (Pala et al., 2010). Dominansi ikan yuwana juga dikarenakan lemuru protolan tertangkap hampir pada setiap bulan di perairan Selat Bali (Wudji et al., 2012).

\subsection{Komposisi Spesies yang Tertangkap}

Berdasarkan hasil pengamatan secara observasi didapat yaitu sebanyak $100 \%$ ikan target Lemuru (Sardinella lemuru). Selain melakukan observasi secara langsung, pengambilan data juga dilakukan dengan wawancara kepada nelayan menggunakan kuisioner yang terdiri dari 3 pertanyaan sesuai dengan kriteria skorsing pada indikator komposisi spesies. Dari hasil wawancara yang dilakukan seluruh responden, proporsi ikan utama memiliki persentase lebih besar dari ikan sampingan (bycatch). Jenis alat tangkap yang digunakan dapat memengaruhi proporsi ikan. Sehingga berdasarkan persentase tersebut didominasi oleh ikan target yaitu ikan Lemuru. Dengan ini skor yang didapat dari indikator komposisi spesies adalah 3. Hal ini dikarenakan nelayan menggunakan alat tangkap gillnet (jaring insang) dengan ukuran 1 inci. Jaring insang adalah alat tangkap pasif yang dapat digunakan sebagai alat penangkapan untuk sumberdaya ikan pelagis, dimana target utamanya yaitu ikan pelagis kecil (Pratiwi et al., 2020). Hasil tangkapan dari suatu alat tangkap yang didominasi oleh ikan target menunjukkan bahwa alat tangkap tersebut selektif (Adel, 2017). Hal ini sejalan dengan pernyataan Sudirman et al. (2004), selektifitas tinggi pada alat tangkap terjadi apabila suatu alat tangkap hanya menangkap target spesies dengan ukuran tertentu.

\subsection{Range Collapse Sumber Daya Ikan}

Range collapse merupakan suatu fenomena yang terjadi apabila stok ikan mengalami overfishing yang terjadi akibat kegiatan eksploitasi secara terus menerus sehingga stok ikan semakin menipis yang mengakibatkan sulitnya nelayan dalam menentukan lokasi penangkapan ikan sehingga terjadi range collapse. Nelayan yang mendaratkan ikan di PPI Kedonganan dengan ikan target ikan Lemuru membutuhkan waktu kurang lebih 15-30 menit menuju lokasi. Hasil wawancara dengan nelayan terkait daerah penangkapan ikan dalam 10 tahun terakhir bervariasi. Terdapat $57 \%$ nelayan menyatakan bahwa daerah penangkapan ikan relatif tetap 
dan sebanyak $43 \%$ nelayan menyatakan daerah penangkapan ikan semakin sulit.

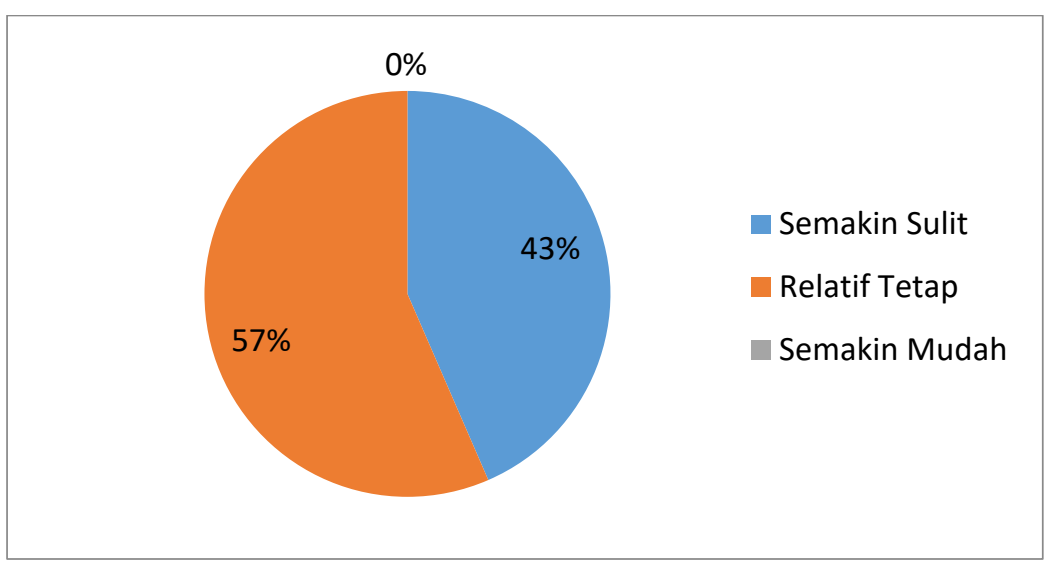

Gambar 3.

Range Collapse Sumber Daya Ikan

Hasil tersebut menunjukkan bahwa daerah tangkapan ikan lemuru masih tergolong relatif tetap dari daerah penangkapan tahuntahun sebelumnya. Namun nelayan juga tetap berpindah lokasi untuk mendapatkan hasil yag maksimal. Perubahan daerah tangkapan dipengaruhi oleh faktor utama sifat ikan lemuru yang hidupnya beruaya. Ruaya merupakan perpindahan ikan karena adanya kepentingan untuk melakukan proses reproduksi, kepentingan mencari makan dan ruaya terjadi karena perubahan lingkungan perairan (Himelda et al., 2011).

\subsection{Spesies ETP (Endangered, Threatened, and Protected)}

Spesies ETP (Endangered, Threatened, dan Protected) merupakan spesies yang dilindungi. Hasil observasi secara langsung dan wawancara selama penelitian menunjukkan bahwa didapat ikan Lemuru yang merupakan ikan target dengan nama ilimiah Sardinella lemuru. Berdasarkan status IUCN ikan lemuru masuk kedalam status Near Threatened (NT) atau hampir terancam punah. Kemudian pada penilaian status konservasi CITES, Ikan Lemuru termasuk dalam status (Not Evaluated) sehingga tidak masuk kedalam daftar CITES (tidak adanya spesies ETP yang tertangkap ataupun terlihat saat nelayan melaut. Nelayan menyatakan tidak adanya spesies ETP yang ditemukan karena daerah tangkapan tidak terlalu jauh dari pesisir dan pada saat itu musim ikan yang terlihat hanya ikan target yaitu ikan Lemuru. Berdasarkan hasil yang didapat, indikator ETP (Endangered, Threatened, dan Protected)

\subsection{Penilaian Status Domain Sumber Daya Ikan Lemuru}

Hasil dari penilaian setiap indikator EAFM pada Domain Sumberdaya Ikan kemudian divisualisasikan dalam bentuk flag modeling. Terdapat 3 warna dari hasil penilaian domain sumber daya ikan. Berdasarkan hasil penilaian EAFM dengan indikator yang divisualisasikan dengan flag modelling didapat bahwa dua indikator diantaranya komposisi spesies dengan hasil proporsi ikan target lebih banyak dan spesies ETP dengan hasil tidak ada spesies ETP yang ditemukan ataupun tertangkap, sehingga flag modeling berwarna hijau. Indikator tren ukuran ikan dengan hasil ukuran ikan dari tahun ke tahun relatif tetap dan hasil range collapse relatif tetap sehingga flag modelling berwarna kuning. Indikator proporsi ikan yuwana berwarna merah karena ikan target yang didapat merupakan ikan yang belum matang gonad. Berdasarkan hasil penilaian EAFM dengan indikator yang dimodifikasi didapatkan nilai komposit sebesar 66,7 dengan visualisasi flag modelling berwarna hijau muda. Hal ini menandakan bahwa PPI Kedonganan memiliki status sumber daya ikan yang baik dalam penerapan EAFM pada Domain Sumber Daya Ikan. 
Tabel 5. Hasil Penilaian EAFM

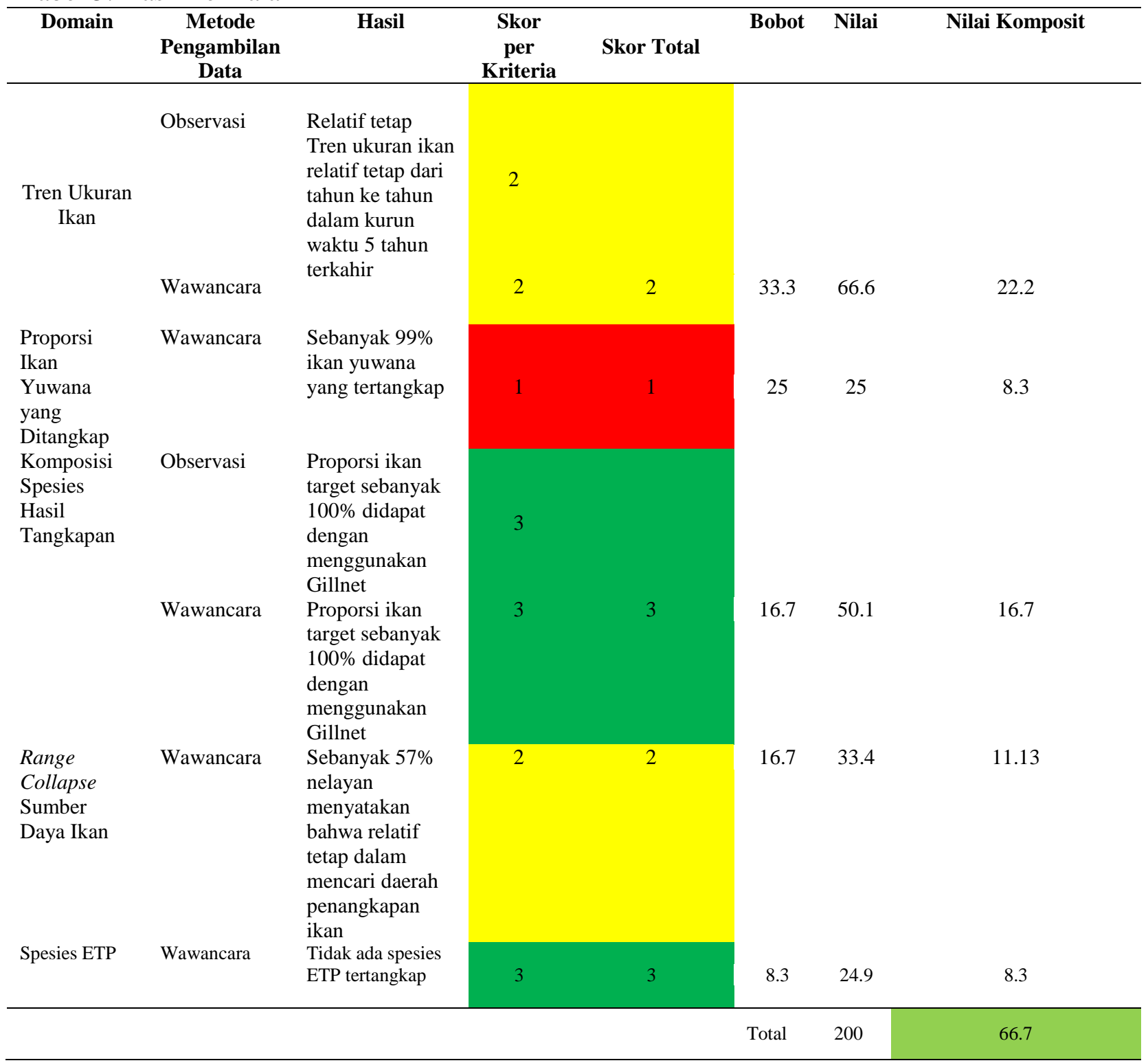

Nilai Komposit EAFM untuk PPI Kedonganan memiliki status baik dengan flag modelling berwarna hijau muda. Setiap indikator memiliki pengaruh dan peranan yang saling berkaitan dalam pelaksanaan pengelolaan perikanan. Dari hasil penilaian yang didapat akan menghasilkan saran dalam upaya tidak lanjut untuk perbaikan dalam implementasi EAFM. Indikator proporsi ikan yuwana mendapat nilai sangat buruk dengan warna merah, hal ini diakibatkan oleh penangkapan yang tidak tepat baik dari waktu penangkapan maupun ukuran alat tangkap yang digunakan.

PPI Kedonganan yang perairanya berada pada WPP 573 sebagai mana dijelaskan bahwa WPP atau Wilayah Pengelolaan Perikanan merupakan bass data bagi tata kelola perikanan Indonesia yang dapat dijadikan kawasan implementasi pendekatan ekosistem dalam pengelolaan perikanan berkelanjutan. Kaijan terkait penilaian status pada Domain Sumber Daya Ikan pada wilayah WPP-RI lainnya dapat dilihat pada Tabel 6 . 
Tabel 6. Persebaran Status Domain Sumber Daya Ikan di WPP-RI

\begin{tabular}{llcc}
\hline No. & \multicolumn{1}{c}{ Daerah Penangkapan } & WPP & $\begin{array}{c}\text { Status Bendera Domain Sumber } \\
\text { Daya Ikan }\end{array}$ \\
\hline 1. & Pantai Kedonganan, Bali & 573 & Hijau Muda \\
2. & Pulau Morotai $(* 1)$ & 715 & Hijau Muda \\
3. & Raja Ampat $(* 2)$ & 715 & Hijau Muda \\
4. & Kepulauan Aru $(* 2)$ & 718 & Hijau \\
5. & Perairan Selat Lombok $(* 3)$ & 573 & Hijau Muda \\
6. & Perairan Laut Sulawesi $(* 4)$ & 716 & Kuning \\
$7 . \quad$ Laut Jawa $(* 5)$ & 712 & Merah \\
\hline Sumber: *1). Abdullah et al. (2020); *2) & Mulyana $(2018) ; * 3)$ Putra et al. $(2020) ; * 4)$ \\
Puansalaing et al. $(2021) ; * 5)$ Budiarto $(2015)$. &
\end{tabular}

Perairan Pantai Kedonganan termasuk ke dalam pengelolaan pemanfaatan sumber daya ikan dalam kondisi baik. Seperti halnya pada WPP 573 di Perairan Selat Lombok, WPP 715 di perairan Pulau Morotai dan Raja Ampat yang tergolong ke dalam kondisi baik pada domain sumber daya ikan. Lebih lanjut pada WPP 718 di Kepulauan Aru tergolong ke dalam kondisi yang sangat baik. Berbeda halnya dengan penelitian Puansalaing (2021) pada WPP 716 di perairan Sulawesi status pengelolaan sumber daya ikan ditandai dengan flag modelling berwarna kuning yang mengindikasikan pengelolaan pemanfaatan sumber daya ikan tergolong sedang. Budiarto (2015) melaporkan status pengelolaan perikanan di WPP 712 tergolong buruk. Perairan dengan flag modelling berwarna hijau muda hingga hijau telah menjalankan pengelolaan EAFM dengan baik. Seperti halnya di perairan Raja Ampat dan Kepulauan Aru menerapkan pengelolaan mainting strategy dengan mempertahankan dan menjaga status kondisi yang telah ada dan didukung dengan tindakan tegas terhadap penggunakan alat tangkap terlarang (Mulyana, 2018). Perbedaan status pada setiap daerah dikarenakan adanya perbedaan situasi dalam pengelolaan sumber daya ikan.

\subsection{Saran Pengelolaan pada Domain Sumber Daya Ikan di PPI Kedonganan}

Pengelolaan perikanan bertujuan untuk memenuhi tujuan dalam mencapai tujuan sosial dan kebutuhan manusia dalam pangan dan manfaat ekonomi melalui tindakan pengelolaan yang menitikberatkan pada aktivitas penangkapan dan target sumber daya (NWG, 2014). Saran pengelolaan yang dapat diberikan dalam pengelolaan pendekatan ekosistem pada Domain Sumber Daya Ikan di PPI Kedonganan adalah sebagai berikut:

1. Pengawasan dan edukasi terhadap proporsi ikan yang ditangkap agar kedepannya tidak tertangkap lagi ikan yang belum matang gonad (yuwana) seperti pembatasan terhadap jadwal kegiatan nelayan sesuai dengan musim penangkapan. Sebaiknya dilakukan perbaikan perubahan ukuran mata jaring yang digunakan agar ikan dapat tertangkap pada kematangan gonad yang tepat. Sehingga perikanan khususnya ikan lemuru dapat dimanfaatkan secara berkelanjutan. Atas dasar tersebut pemerintah dapat mengeluarkan peraturan mengenai ukuran mata jaring yang dapat digunakan.

2. Pengawasan dan edukasi terkait eksploitasi ikan untuk mewujudkan perikanan yang berkelanjutan. Seperti halnya hasil dari range collapse sumber daya ikan relatif tetap dari tahun ke tahun, namun dalam penangkapan ikan yang dilakukan terjadi perpindahan lokasi penangkapan. Hal ini dapat diindikasikan adanya penurunan kondisi perairan dan perikanan akibat eksploitasi yang terusmenerus. Dalam hal ini peran pemerintah dan kelompok nelayan sangat berpengaruh terhadap keberlanjutan perikanan yang didaratkan di PPI Kedonganan, khususnya ikan lemuru (Sardinella lemuru). 
Saran pengelolaan sumber daya ikan pada indikator dengan hasil yang baik hingga baik sekali dapat dilakukan perbaikan, evaluasi, monitoring, dan upaya untuk mempertahankan hasil baik yang telah didapat. Selain itu, dengan peran serta dari semua steakholder untuk ikut menjaga dan mengawasi pemanfaatan sumber daya ikan, maka perikanan akan tetap terjaga dan lestari.

\section{SIMPULAN DAN SARAN}

\subsection{Simpulan}

Kondisi sumber daya ikan pada komoditas ikan lemuru di PPI Kedongan mengalami penurunan hasil produksi pada tahun 2017, kemudian meningkat kembali hasil produksi di tahun 2018. Penurunan ini diduga karena cuaca buruk sehingga menyebabkan musim paceklik. Ikan lemuru sebagai ikan target yang ditangkap di perairan kedonganan dan didaratkan di PPI Kedonganan. Nelayan di PPI Kedonganan merupakan nelayan dengan wilayah penangkapan pada WPP 573. Status sumber daya ikan lemuru dengan pendekatan EAFM di PPI Kedonganan mendapat status baik dengan flag modeling berwarna hijau muda, dengan nilai komposit 66,7. Dari 5 indikator EAFM pada Domain Sumber Daya Ikan yang telah ditelit, terdapat 2 indikator dengan hasil sangat baik, yaitu indikator Komposisi Spesies Hasil Tangkapan dan Spesies ETP. Kemudian 2 indikator dengan status baik terdapat pada Tren Ukuran Ikan, dan Range collapse Sumber Daya Ikan. Sedangkan flag modeling berwarna merah dengan status buruk terdapat pada Indikator Proporsi Ikan Yuwana. Hasil baik dari penilaian EAFM pada Domain Sumber Daya Ikan masih perlu adanya perbaikan dalam aktivitas perikanan tangkap seperti edukasi terhadap pembatasan kegiatan penangkapan dan penggunaan diameter ukuran jaring yang tepat, serta pengawasan dan evaluasi terhadap kegiatan penangkapan.

\subsection{Saran}

Saran yang dapat diberikan dari penelitian ini yaitu yang baik dalam penerapan EAFM di PPI Kedonganan diharapkan dapat dijadikan bahan acuan atau pertimbangan dalam pengelolaan perikanan tangkap di perairan sekitar PPI Kedonganan ataupun sebagai bahan evaluasi pada daerah lainnya dengan potensi perikanan yang tinggi. Saran yang diberikan pada penelitian selanjutnya adalah penelitian pada domain sumber daya ikan yang didaratkan di PPI Kedonganan dapat dikaji dalam kurun waktu 1 tahun, sehingga didapatkan penilaian yang lebih menyeluruh serta diharapkan dapat mencari seluruh indikator yang terdapat pada domain sumber daya ikan.

\section{DAFTAR PUSTAKA}

[NWG EAFM] National Working Group on Ecosystem Approach to Fisheries Management. 2014. Modul Indikator Pengelolaan Perikanan Dengan Menggunakan Pendekatan EAFM (Ecosystem Approach To Fisheries Management). Jakarta (ID): Direktorat Sumber Daya Ikan Kementerian Kelautan dan Perikanan Republik Indonesia

[PPI] Pangkalan Pendaratan Ikan Kedonganan. 2019. Data Statistik PPI Kedonganan 2019. Badung (ID): Pangkalan Pendaratan Ikan Kedonganan.

[PPNP] Pelabuhan Perikanan Nusantara Palabuhanratu. 2014. Data Statistik PPN Palabuhanratu 2014. Jawa Barat (ID): Pelabuhan Perikanan Nusantara Palabuhanratu.

Abdullah, R.M., Taerin, I., Akbar, N. 2020. Evalasi Pengelolaan Perikanan Tuna Berdasarkan Pendekatan Ekosistem di Kabupate Pulau Morotai. Jurnal Enggano. 5(2); 143-151 hlm.

Adel YS. 2017. Pengelolaan sumber daya perikanan capungan banggai (Pterapogon kauderdi, Koumans 1933) dengan Pendekatan Ekosistem: Studi Kasus Pulau Banggai Kabupaten Banggai Laut [tesis]. Bogor: Sekolah Pascasarjana Institut Pertanian Bogor.

Adrianto, L., Habibi, A., Fahrudi, A., Azizy, A., Susanto, H.A., Kamal, M.M., Wisudo, S.H., Wardiatno, Y., Raharjo, P., Naution, Z., dan Yonvitner.2014. 
Indikator untuk pengelolaan perikanan dengan pendekatan ekosistem (Ecosystem Approach to Fisheries Management). Modul. Direktorat Sumber Daya Ikan, Kementrian Kelautan dan Perikanan dan National Working Group (NWG) on EAF.

Budiarto, A., Adrianto L., Kamal M. 2015. Status Pengelolaan Perikanan Rajungan (Potunus Pelagic) dengan Pendekatan Ekosistem di Laut Jawa (WPPNRI 712). Institut Pertanian Bogor. Jurnal kebijakan Perikanan Indonesia. 1(1) Hal. 9-24

Desniarti, Fauzi A., Monintja, D,R., Boer, M. 2006. Analisis Kapasitas Perikanan Pelagis di Perairan Pesisir Propinsi Sumatera Barat . Jurnal Ilmu-ilmu Perairan dan Perikanan Indonesia (2): 117-124

Fréon, P., P. Cury, L. Shannon, and C. Roy. 2005. Sustainable exploitation of small pelagic fish stocks challenged by environmental and ecosystem changes. Bulletin of Marine Science. 76(2):385$462 \mathrm{hlm}$.

Himelda, Wiyono, E.S., Purbayanto, A., Mustaruddin. 2011. Analisis Sumberdaya Perikanan Lemuru (Sardinella Lemuru Bleeker 1853) di Selat Bali. Marine Fisheries. 2(2); 165$176 \mathrm{hlm}$.

Merta I.G.S. 1992. Dinamika Populasi Ikan Lemuru (Sardinella lemuru) di perairan Selat Bali dan Alternatif Pengelolaannya. Disertasi. IPB. Bogor.

Pala, M., Yuksel, M. 2010. Comparison of the Catching Efficiency of Monofilamen Gill Net With Different mesh Size. Journal of Animal and Veterinary Advances. Vol. 7. 1146-1149 hlm.

Pertami, N.Y., Rahardjo, M.F., Damar, A., Nurjaya, I.W. 2020. Ikan Lemuru, Primadona Perikanan Selat Bali yang Menghilang.Warta Iktiologi. 4(3); 1-7 hlm.

Pratiwi, M.A., Ernawati, N.M., Wijayanti, N.P.P. 2020. Penilaian Status
Sumberdaya Ikan Hasil Tangkapan Dominan yang Didaratkan di PPI Kedonganan dengan Pendekatan MultiCriteria Analysis(MCA). Journal of Marine and Aquatic Sciences 6(2); 152$160 \mathrm{hlm}$.

Puansalaing, D.M., Budiman, J., Boneka, F.B., Makapedua, D.M., Lasut, M.T., Ngangi, E.L.A., Sumilat, D.A., Darmono, O.P. 2021. Pengelolaan Perikanan Ikan Layang (Decapterus spp.) di Perairan Laut Sulawesi, Provinsi Sulawesi Utara, Menggunakan EAFM. Journal Aquatic Science and Management. 9(1): 7-16 hlm.

Putra, I.N.S.A., Restu, I.W., Ekawaty, R. 2020. Kajian Stok Ikan Lemuru (Sardinella lemuru) yang Didaratkan di Pelabuhan Perikanan Pantai Muncar Kabupaten Banyuwangi Provinsi Jawa Timur. Current Trends in Aquatic Science. III(1); 30-38 hlm.

Putra, I.P.Y.P., Arthana, I.W., Pratiwi, M.A. 2020. Penilaian Status Domain Sumber Daya Ikan Berdasarkan Pendekatan Ekosistem untuk Pengelolaan Perikanan Tongkol Krai (Auxis thazard) di Perairan Selat Lombok yang Didaratkan di Desa Seraya Timur, Bali. Jurnal Pengelolaan Perikanan Tropis. 4(2); 29$37 \mathrm{hlm}$.

Sudirman, Mallawa A. 2004. Teknik penangkapan ikan. Jakarta (ID): Rineka cipta.

Sudjana. 2002. Metode Statistika Edisi Keenam. Bandung: Tarsito.

Wujdi, A. S., Wudianto. 2012. Hubungan Panjang Bobot, Faktor Kondisi dan Struktur Ukuran Ikan Lemuru (Sardinella lemuru Bleeker, 1853) di Perairan Selat Bali. Jakarta, Indonesia: Pusat Penelitian Pengelolaan Perikanan dan Konservasi Sumberdaya Ikan.

Mulyana. 2018. Penilaian Indikator EAFM di Kabupaten Raja Ampat dan Kabupaten Kepulauan Aru. Universitas Djuanda Bogor. Jurnal Mina Sains. Vol. 4, No. 1, Hal 1-10. 